\title{
PerCursos
}

\section{Resurgence*: caminhos para descolonização no pensamento de Taiaiake Alfred}

\section{Resumo}

Com o propósito de contribuir para o debate sobre descolonização a partir da perspectiva dos Povos Indígenas, apresentamos a noção de Resurgence elaborada por Taiaiake Alfred, um dos mais importantes pensadores indígenas do Canadá. Alfred propõe sua noção de Resurgence como uma estratégia de rompimento com as relações coloniais de poder que incidem sobre a capacidade dos Povos Indígenas viverem e se desenvolverem de acordo com os seus próprios sistemas de pensamento. Veremos que, além de questionar a dominação colonial, a noção de Resurgence, ancorada nas experiências milenares e na sabedoria dos Povos Indígenas, mostra como preparar o caminho e criar as condições necessárias para uma verdadeira descolonização.

Palavras-chave: Resurgence. Taiaiake Alfred. Pensamento indígena. Descolonização.
Ana Catarina Zema

Pós-doutora em Ciências Políticas pela Université Laval. Doutora

em História Social pela

Universidade de Brasília - UnB.

Brasil

ana.zema@gmail.com

\section{Clarisse Drummond}

Doutora em Ciências Sociais pela Universidade de Brasília - UnB. Mestre em Políticas Sociais e Bacharel em Antropologia pela Universidade de Brasília - UnB.

Brasil

clarisse.drummond@gmail.com

\section{Keyla Pataxó}

Mestre em Direito pela

Universidade de Brasília - UnB.

Brasil

keylathyxaya@hotmail.com

\section{Para citar este artigo:}

ZEMA, Ana Catarina; DRUMMOND, Clarisse; PATAXÓ, Keyla. Resurgence*: caminhos para descolonização no pensamento de Taiaiake Alfred. PerCursos, Florianópolis, v. 22, n.48, p. 354 - 374, jan./abr. 2021. 


\title{
Resurgence *: paths to decolonization in the thought of Taiaiake Alfred
}

\begin{abstract}
To contribute to the debate on decolonization from the perspective of Indigenous Peoples, we present the notion of Resurgence elaborated by Taiaiake Alfred, one of Canada's most important Indigenous thinkers. Alfred proposes his notion of Resurgence as a strategy for breaking away from colonial power relations that focus on Indigenous Peoples' ability to live and develop according to their own thinking systems. We will see that, besides questioning colonial domination, the notion of Resurgence, anchored in the millenary experiences and wisdom of Indigenous Peoples, shows how to prepare the way and create the necessary conditions for a true decolonization.
\end{abstract}

Keywords: Resurgence. Taiaiake Alfred. Indigenous thinking. Decolonization. 


\section{Introdução}

Muito se tem ouvido falar sobre descolonização e descolonizar. No senso comum, o termo é entendido como o processo por meio do qual uma colônia alcança a sua independência do poder colonial. Historicamente, refere-se aos processos de independência dos povos e territórios que foram submetidos à dominação política, econômica, social e cultural pelas metrópoles europeias. A palavra ganha popularidade a partir da década de 1960, durante as lutas por independência dos países no continente africano.

Com o passar do tempo, o termo descolonização adquire uma conotação voltada para transformações no plano ético-político e epistêmico, sobretudo a partir das lutas dos movimentos indígenas em Abya Yala e em Turtle Island'. A descolonização surge como reivindicação política desses movimentos nas cumbres² dos anos 1990 e nas mobilizações em Turtle Island. No entanto, desde que o pensamento decolonial se fez moda, há uma certa vulgarização do debate em torno da descolonização que, além de despolitizar as ideias daqueles que estiveram e estão na linha de frente da luta anticolonial, desconsidera o discurso e as práticas dos Povos Indígenas que, primeiro, levantaram essa bandeira na década de 1990 em Abya Yala e em Turtle Island.

Com o propósito de contribuir para o debate sobre "descolonização" a partir da perspectiva dos Povos Indígenas, apresentamos a noção de Resurgence elaborada por Taiaiake Alfred. Em um primeiro momento, trazemos elementos biográficos para o público lusófono que ainda não conhece esse grande pensador Mohawk. Em seguida,

\footnotetext{
${ }^{1}$ Turtle Island ou Ilha da Tartaruga é um nome tradicional que os Povos Indígenas do Norte usam para se referir à Terra ou à América do Norte. $O$ nome é baseado em uma história de criação comum aos Povos Indígenas da América do Norte. $O$ termo se tornou popular entre os ativistas indígenas e não indígenas para os quais seu uso deve ajudar a compreender a América do Norte e a mudar as concepções sobre o continente.

${ }^{2}$ As cumbres ou reuniões indígenas realizadas nas últimas duas décadas na América Latina tornaram-se cenários de debate, negociação, acordos e de reafirmação da unidade em torno do projeto político indígena continental. Tornaram-se espaços para a articulação e construção coletiva de propostas e definições políticas. Lugares para pensar na construção de um futuro e na interpretação de um passado comum. A celebração de uma cumbre indígena é a oportunidade para a formação de redes, de frentes; um momento para delinear objetivos, estratégias, plataformas de ação e para endossar e modificar agendas. O encontro indígena como um espaço coletivo, é o terreno da diversidade, da multiplicidade de abordagens, experiências e projetos (CAL Y MAYOR, 2007, n.p.).
} 
retomamos as críticas que Taiaiake Alfred faz ao colonialismo no contexto canadense. Essas críticas são fundamentais para a compreensão da virada que o movimento Resurgence representa na medida em que revelam a natureza ativa do colonialismo no Canadá. Num terceiro momento, discutimos a noção de Resurgence e suas principais áreas de incidência: terra, alimentação, linguagem e educação. Finalmente, veremos que o paradigma da Resurgence se apresenta como um caminho plausível para os Povos Indígenas se tornarem os principais atores de uma verdadeira descolonização.

Tomamos como referência principal Taiaiake Alfred, seus escritos e suas palestras. Mas é importante notar que outros pensadores indígenas têm igualmente contribuído com o desenvolvimento das propostas e ideias do movimento de Resurgence, entre eles, Jeff Corntassel, Glen Coulthard e Leanne Betasamosake Simpson. No entanto, como eles mesmos costumam enfatizar, suas contribuições não representam as "vozes autênticas" do movimento e nem constituem os seus "limites essenciais". Para eles, Resurgence é mais um "modo de ser e de resistência", situado geograficamente e alicerçado em práticas e saberes indígenas, do que um "esforço erudito". Por isso, "não pode ser reduzido a um conjunto de parâmetros nem a um grupo selecionado de vozes" (ELLIOTT, 2018, p. 3).

Hoje os escritos indígenas têm despertado grande interesse, no entanto, alguns cuidados devem ser tomados quando nos aproximamos do pensamento e da escrita indígena. Primeiro, é preciso considerar que os Povos Indígenas estão envolvidos em uma luta política; nesse sentido, o caráter político de seus escritos e pensamentos não pode ser subestimado e deve ser respeitado. Segundo, é preciso lembrar que se trata de um pensamento complexo, baseado em experiências e saberes milenares, que busca dar conta de situaçõos difíceis que são as relações coloniais, o sofrimento social por elas gerado e os caminhos para romper com o ciclo de violências. Além disso, acreditamos que conhecer o pensamento político indígena é imprescindível se quisermos realmente compreender os fundamentos de suas reivindicações. 


\section{Taiaiake Alfred: elementos biográficos}

Gerald Taiaiake Alfred é Mohawk de Kahnawá: ke. Kahnawà: ke significa, na língua Mohawk, "lugar das corredeiras", como é chamado o território tradicional situado à margem sul do rio Saint Laurent, no Quebec, próximo à Montreal. Mohawk é o nome dado pelos europeus aos Kanien'kehá: ka, o "povo da pedra". Os Kanien'kehá: ka são a Nação mais oriental do Haudenosaunee, as Seis Nações da Confederação Iroquesa. Historicamente, cuidavam do território de ambos os lados do rio Mohawk e a oeste do rio Hudson, na atual Nova Iorque, de onde protegiam outras partes da Confederação.

Alfred é um dos mais importantes pensadores indígenas da Turtle Island. Autor, educador e ativista com grande projeção no cenário canadense e mundial³ , é doutor em Ciências Políticas e foi professor na Universidade Concordia, em Montreal, e na Universidade de Victoria (UV), na Columbia Britânica, onde foi fundador e diretor do Programa de Estudos sobre Governança Indígena até 2019. Foi também membro do Conselho Mohawk de Kahnawà: ke e assessor da Comissão Real para os Povos Indígenas do Canadá. 4

Em entrevista à Radio Nuxalk em 21 de junho de 202055, ele se apresenta como pai, caçador e escritor, alguém que ajuda nas estratégias das Primeiras Nações, basicamente reafirmando o poder das Nações indígenas para recuperar a sua terra. Nessa entrevista, ele explica que desde que deixou a Universidade de Victoria, trabalha diretamente com as comunidades, buscando fortalecer a soberania e a nacionalidade dos Povos Indígenas (ALFRED, 2020).

\footnotetext{
3 Taiaiake Alfred foi contemplado com fundos da Canada Research Chair, foi premiado como melhor colunista indígena pela Associação de Jornalistas Indígenas Americanos (Native American Journalists Association) e recebeu o prêmio Nacional de Realização Indígena (National Aboriginal Achievement Award).

${ }^{4}$ A Comissão Real sobre os Povos Indígenas (Commission Royale sur les Peuples Autochtones) foi instaurada pelo Parlamento do Canadá em agosto de 1991, alguns meses após a Crise de Oka, para investigar as mudanças nas relações entre os Povos Indígenas, o governo e a sociedade canadense como um todo. Em seu relatório final, publicado em 1996, em 5 volumes, foram apresentadas 400 recomendações visando melhorar as relações entre os governos federal e provinciais e as populações das 70 Nações Indígenas do Canadá.

5 It's all about the Land. Entrevista concedida à Radio NuxalK, 21 de junho de 2020. Disponível em: <https://taiaiake.net/>. Acesso em: 10 nov. 2020.
} 
Alfred cresceu em meio às lutas políticas da comunidade Mohawk de Kahnawà: ke. Em uma de suas conferências ${ }^{6}$, ele explica que sua consciência política começa na infância (ALFRED, 2018), em 1973, quando assistiu a uma série de levantes e manifestações das Primeiras Nações em Turtle Island, e com a descoberta do que significava ser "índio" (Indian), quando ainda se usava esse termo. Nessa conferência, ele revela a influência do movimento Black Power na formação do Red Power. Essa influência é marcante em toda sua obra, assim como as referências à Frantz Fanon e à Vine Deloria Jr. Para além dessas influências, seus pensamentos e escritos estão ancorados em experiências de vida que extrapolam o mundo acadêmico.

No Canadá, Alfred ficou conhecido por suas críticas contundentes à política de reconciliação do governo e por sua visão original sobre os caminhos possíveis para uma verdadeira descolonização e autodeterminação dos Povos Indígenas. É autor de três livros: Heeding the Voices of Our Ancestors (1995); Peace, Power, Righteousness (1999) e Wasáse: Indigenous Pathways of Action and Freedom (2005), além de vários artigos e palestras.

Em Heeding the Voices of Our Ancestors (Atendendo às vozes de nossos ancestrais), ele apresenta uma análise do nacionalismo indígena. Seu propósito é "examinar o processo de construção de objetivos no contexto da política comunitária indígena norte-americana" (ALFRED, 1995, p. 4). Ele trata do reaparecimento de um conjunto de objetivos e estratégias incorporados na cultura política tradicional dos Mohawk que defendem "a afirmação de uma forma radical de soberania indígena, em oposição a um processo de mudança política que leva a uma maior integração com o Canadá ou os Estados Unidos" (ALFRED, 1995, p. 4). Ele mostra como os valores e princípios tradicionais dos Mohawk sempre permearam a cultura política de Kahnawà: ke e descreve como o conselho de bando, organizado sob os auspícios da Lei dos Índios, foi transformado em um instrumento de autogoverno Mohawk.

\footnotetext{
6 From Red Power to Reconciliation, conferência apresentada no Instituto para as Humanidades da Universidade Simon Fraser, por ocasião do congresso "Then and Now: 1968-2018", em Vancouver, BC, 2 de novembro de 2018. Nessa conferência, Taiaiake Alfred traça a história do movimento indígena da América do Norte desde os anos 1970, quando surge o Red Power nos Estados Unidos da América sob forte influência do Black Power.
} 
Após uma análise histórica, ele explica, nesse livro, o efeito de alguns acontecimentos marcantes na sua comunidade: a Crise de 1990 e outros confrontos com o Estado. Esses acontecimentos foram significativos como pontos de referência para o avanço do povo Mohawk na realização dos seus objetivos. Cada crise, ele escreve, "aumenta a expectativa de uma eventual resolução das queixas de longa data da comunidade contra o Estado, e traz à tona contradições internas que ainda precisam ser resolvidas na comunidade" (ALFRED, 1995, p. 3). As crises e os conflitos dão o impulso necessário para as "reavaliações da história e da cultura, essenciais à manutenção de um conjunto saliente de valores políticos" (ALFRED, 1995, p. 3). Com esses aprendizados, ele constata a necessidade crescente de afirmação do nacionalismo e da soberania Mohawk.

Em 1999, publica seu segundo livro: Peace, Power and Righteousness: an Indigenous Manifesto (Paz, Poder e Retidão: um Manifesto Indígena), como uma chamada à ação direcionada aos Povos Indígenas oprimidos da Turtle Island e uma mensagem para os não indígenas de todo mundo. Nesse manifesto, Alfred propõe que o conceito de descolonização seja pensado com relação aos dilemas que as lideranças indígenas enfrentam quando precisam fazer escolhas políticas em suas interações com o "poder branco". Ele reconhece a necessidade de que os Povos Indígenas se libertem das opressões do colonialismo e argumenta que, para uma autodeterminação autêntica, é preciso preservar as Nações indígenas, restaurar o orgulho de suas tradições, alcançar a autossuficiência econômica, desenvolver a independência da mente e demonstrar coragem na defesa das terras e direitos.

Em seu último livro, Wasáse: Indigenous Pathways of Action and Freedom (Wasáse: Caminhos Indígenas de Ação e Liberdade), Taiaiake Alfred faz um apelo para que os Povos Indígenas se unam na resistência às estruturas coloniais de opressão. Wasáse é o nome de uma dança tradicional Mohawk que valoriza "a unidade, a força e a vontade de agir”. A partir da descrição dessa dança Rotnishonni do trovão (Rotnishonni Thunder Dance) que é invocada como uma cerimônia de guerra, Alfred explica o caminho do guerreiro contemporâneo para uma mudança significativa e revolucionária. O chamado à mudança radical nas comunidades deve ocorrer por meio da paz. Alfred conhece e considera o papel da violência na resistência colonial. No entanto, ele lembra que existe 
um desejo de paz no coração de todos os guerreiros, uma vez que o Onkwehonwe (povo original) nasce com uma memória de paz. Essa exigência de paz deve motivar os Povos Indígenas para uma resistência significativa. Assim, Wasáse, a cerimônia de guerra, é uma cerimônia que promove e ensina a paz. Segundo Taiaiake Alfred, a verdadeira coragem de um guerreiro reside em viver uma vida diária fundamentada nos ensinamentos e práticas espirituais dos seus antepassados. Taiaiake conclama para uma mudança revolucionária que, para ocorrer, deve estar enraizada no ressurgimento pacífico da espiritualidade tradicional.

Uma constante em todos seus livros e escritos, é esse chamado que Taiaiake Alfred faz aos Povos Indígenas para que retornem às suas tradições e à espiritualidade indígena na sua busca pela recuperação de suas próprias estruturas políticas ou autogoverno. De forma muito honesta e humilde, em Wasáse, Taiaiake admite que as suas afirmações anteriores sobre o tradicionalismo eram ingênuas e ignoravam as realidades estruturais de dependência no seio das comunidades indígenas. Por isso, em seu último livro, ele propõe desafiar essa dependência num esforço comum para enfrentar o poder colonial a partir dos princípios de Wasáse. Em todos seus escritos, ele fala das lutas para descolonizar e convida os leitores indígenas e não indígenas para uma ação crítica de descolonização. Antes de apresentarmos suas propostas para a Resurgence como caminho para a descolonização, julgamos importante sublinhar algumas de suas críticas ao colonialismo canadense e à política da reconciliação.

\section{Críticas ao colonialismo ou as mentiras do Canadá colonial}

Ao longo da obra de Alfred, seus escritos e palestras, encontramos diversas críticas ao colonialismo e ao modo como as narrativas coloniais, desde os processos de conquista, foram incorporadas e estão profundamente conectadas, emocional e psicologicamente, às histórias de todos os Povos Indígenas, na forma de mentiras assumidas como verdades históricas (ALFRED, 2011).

Toda a história do Canadá, para Alfred (2003), se construiu a partir de mentiras que, por sua vez, estão na base de uma "mitologia colonial" que hoje assume a forma de 
premissas constitucionais e de estruturas institucionais. A mitologia do colonialismo difundiu mentiras históricas como, por exemplo, a criação do artifício jurídico-legal da Terra Nullius ou a presunção de soberania da Coroa Britânica enquanto estratégia para adquirir os territórios tradicionalmente ocupados pelas Nações Indígenas desde tempos imemoriais, e que nunca foram cedidos ao Império Britânico (ALFRED, 2003).

Outro grande imperativo do colonialismo, enquanto narrativa mítica fundada em mentiras, é o enquadramento temporal dos danos e impactos do colonialismo sobre as vidas dos Povos Indígenas em um passado remoto e longínquo. Nessa perspectiva, que é amplamente difundida a partir dos discursos oficiais do Estado canadense, os chamados “erros do passado" estariam já superados.

Trazendo as consequências das mentiras coloniais para o cenário mais atual, Alfred ressalta a condição de pobreza e dependência estrutural que caracteriza a situação dos Povos Indígenas no Canadá, como se fossem cidadãos de “quarto mundo":

[...] nosso povo está vivendo vidas insalubres, são infelizes, são disfuncionais, não estão perpetuando as coisas que em suas vidas levam à felicidade, à paz, a bons relacionamentos e a uma relação sustentável numa base de respeito entre si, com a terra e com outros povos. (ALFRED, 2003, n.p., tradução nossa)

Isso ocorre porque as narrativas coloniais destroem o pensamento dos povos dominados, impedindo-os de viverem de acordo com os seus sistemas culturais (ALFRED, 2003). As consequências das mentiras coloniais para os Povos Indígenas são descritas em termos de alienação, separação e desconexão:

A colonização é a desconexão da terra, a desconexão de nós mesmos, e de nossa cultura. A manifestação desta desconexão é a alienação que sentimos como resultado de estarmos presos entre dois mundos, de não sermos capazes de vivermos vidas autênticas. (ALFRED, 2018, n.p., tradução nossa) 
O poder de introjeção das narrativas coloniais perpetua, assim, a alienação, a separação e a desconexão, moldando todas as formas de existência, memórias, identidades e relações político-econômicas dos Povos Indígenas. E, para mostrar como, ainda hoje, as narrativas coloniais são atualizadas, Alfred avança para as chamadas políticas de reconciliação, amplamente difundidas no Canadá como forma de reparar os sobreviventes indígenas da política de internação compulsória que teve lugar no país por mais de um século e afastou crianças indígenas de suas famílias. A última Escola Residencial Indígena do Canadá foi fechada apenas no ano de 1996.

Para Alfred (2018), tais políticas, longe de corresponderem a iniciativas honestas de reconciliação entre indígenas e não indígenas, apresentam-se como "agendas políticas" de conteúdo programático que trazem alívio a toda uma sociedade colonizadora que sofre com o peso moral de um passado calcado na imposição de traumas históricos que nunca poderão ser reparados ou materialmente compensados. $\mathrm{O}$ que não significa que Alfred se oponha ao pagamento de indenizações materiais às famílias, muito pelo contrário. Assim como os pedidos de desculpas, desde que honestos, eles fazem parte do processo de reconciliação, mas não são o seu objetivo maior e tampouco representam o seu fechamento.

Por todas essas razões, para Alfred (2003), as narrativas de controle que integram o poder colonial precisam ser descortinadas e reveladas: "Algo foi roubado, mentiras foram ditas e nunca foram corrigidas [...] Temos que ter conhecimento para ter verdade, e o que temos hoje no lugar do conhecimento, é a mitologia do colonialismo. Temos uma mitologia no lugar da verdade". Enquanto o discurso pacificador da reconciliação não for afastado de seu viés recolonizador, não será possível construir uma ideia de restituição como passo para a criação de uma justiça e uma sociedade moral. E o primeiro passo para a reconciliação, é a restituição territorial:

Sem a restituição massiva aos Povos Indígenas, coletivamente e como indivíduos, incluindo a terra, as transferências de fundos federais e provinciais; a reconciliação e outras formas de compensação por injustiças contínuas e danos passados cometidos contra a terra e os Povos Indígenas, absolverão, permanentemente, as injustiças coloniais e 
são, em si mesmas, injustiças adicionais. (ALFRED, 2009b, p. 185, tradução nossa)

Do mesmo modo, sem o reconhecimento da liberdade e da autodeterminação, sem autossuficiência econômica e sem soberania alimentar, qualquer reconciliação não passa de "discurso pacificador" que funciona mais para aliviar a consciência dos colonos e absolver a responsabilidade dos governos do que transformar o relacionamento entre indígenas e o resto do Canadá (ALFRED, 2009b).

\section{Resurgence}

O paradigma de Resurgence se desenvolveu nos últimos anos como um “movimento intelectual e político dos indígenas no Canadá” (ELLIOT, 2018, p. 1). Suas propostas partem de três premissas:

1) o colonialismo é uma estrutura ativa de dominação baseada na eliminação das sociedades indígenas e não apenas em sua subjugação;

2) o ambiente normativo-discursivo prevalecente reflete este imperativo, apesar das mudanças no sentido de melhor enfrentar a injustiça colonial e;

3) os Povos Indígenas devem, por conseguinte, sempre que possível, afastar-se deste ambiente hostil e canalizar suas energias em programas independentes de renovo social, cultural, espiritual e físico. (ELLIOTT, 2018, p. 1, tradução nossa)

O primeiro e o segundo pontos foram tratados no item anterior. Neste tópico, avançaremos sobre o terceiro ponto que é o que mais caracteriza o movimento de Resurgence, segundo Michael Elliott (2018).

Após tecer suas críticas ao colonialismo no Canadá liberal e à política de reconciliação, Alfred explica que é impossível transformar a ordem colonial desde seu interior, ou seja, por meio dos canais, arenas e discursos que disponibiliza. Para ele, até aqui, esses canais, arenas e discursos não asseguraram a sobrevivência dos indígenas nem 
realizaram avanços no sentido de uma verdadeira descolonização. Por isso, ele considera que, neste contexto de "recolonização" sustentado pelo paradigma da reconciliação no Canadá, não há maneira de descolonizar (ALFRED, 2017, p. 11). A única maneira de se libertar do colonialismo canadense seria por meio do que ele chama de Resurgence, ou seja, um "renascimento de uma indianidade genuína baseada na terra" (ALFRED, 2017, p. 12). Para Alfred, “o caminho para combater a colonização é através da reculturação e do recentramento de si nas suas terras de origem" (ALFRED, 2017, p. 12). Por reculturação e recentramento de si nas suas terras de origem, Alfred refere-se ao restabelecimento da ligação que foi rompida pelo colonialismo com a terra e com a cultura.

Enquanto estratégia de "retorno ao território" e "retorno a si", as propostas de Taiaiake Alfred para a Resurgence Indígena no contexto do colonialismo canadense pretendem, não apenas corrigir as limitações das políticas de reconciliação, mas modificar a dimensão subjetiva da relação colonial e reduzir a assimetria de poder entre as Primeiras Nações e o Estado (PAQUET, 2017).

Por meio de "atos e práticas quotidianas", a Resurgence interpela os Povos Indígenas a recuperarem sua identidade e sua dignidade individual e coletivamente (ALFRED; CORNTASSEL, 2005). Esses atos e práticas do quotidiano são modalidades de ser, de agir e de resistir já profundamente enraizadas nas comunidades indígenas. Ao invés de buscar soluções em programas de ação vindos de fora ou gastar energia em tentativas de modificar as condições do colonialismo existente, a ideia é encontrar alternativas nas próprias práticas e saberes indígenas e reorientar a energia coletiva para o restabelecimento da ligação com a terra, com a cultura e com a comunidade. A sobrevivência dos Povos Indígenas e a descolonização dependem dessa reorientação coletiva de energias capaz de criar realidades sociais alternativas no aqui e agora. Ao restabelecer a ligação com a terra, com a cultura e com a comunidade e, ao recuperar as estruturas de governança e as economias, "as oportunidades de viver de forma autóctone nos tempos contemporâneos poderão ser potencializadas e poderão ser feitos progressos no sentido de transformar o status quo colonial" (ELLIOTT, 2018, p. 2).

Antes dessa reorientação coletiva de energias para descolonização, Taiaiake Alfred e Jeff Corntassel (2005) explicam que a transformação acontece primeiro no nível 
individual. Os caminhos indígenas de "autêntica ação e luta pela liberdade começam com pessoas que transcendem o colonialismo numa base individual” (ALFRED, 2005, p. 612). Como um ressurgir contra os processos de aniquilação e humilhação inerentes ao colonialismo, a "indianidade é reconstruída, reformulada e vivida ativamente" (ALFRED, 2005, p. 612). Para isso, eles apresentam o que chamam de "cinco mantras de um movimento indígena ressurgente": 1) Terra é Vida; 2) Língua é Poder; 3) A liberdade é o Outro Lado do Medo; 4) Descolonize a sua Dieta e 5) A mudança acontece em um Guerreiro de cada vez (ALFRED, 2005, p. 613). Relacionaremos esses cinco mantras com as quatro incidências da Resurgence: terra, linguagem, alimentação e educação, como proposto na introdução.

O primeiro mantra "Terra é Vida" trata do chamado para que os Povos Indígenas se reconectem com o território e com a geografia da sua herança indígena. A experiência de "viver o território" e "sentir o território" possibilita a compreensão dos ensinamentos e valores dos antepassados; permite recuperar sua força e aprender o autossustento de modo a se tornar independente do poder colonial, o que é compreendido como um processo "regenerativo de uma existência indígena autêntica e autônoma" (ALFRED; CORNTASSEL, 2005, p. 613). A reconexão com a Terra propicia autonomização e independência. Esse aspecto é crucial, uma vez que um dos maiores problemas apontados por Taiaiake Alfred é a dependência financeira do Estado e suas consequências psicológicas:

A solução para o problema da dependência psicológica e financeira das Primeiras Nações em relação ao Estado, causadas pelo colonialismo, é a devolução de terras às Primeiras Nações e o restabelecimento da presença das Primeiras Nações nos territórios e de suas conexões com os seus territórios. (ALFRED, 2009a, p. 54, tradução nossa)

Alfred lembra a recomendação feita pela Comissão Real sobre os Povos Indígenas, em seu relatório de 1996, de devolver a terra para as Primeiras Nações em larga escala e reestruturar a lei de modo que o acesso e o uso de seus territórios ancestrais sejam permitidos e facilitados. Ele propõe uma gestão integral da terra que se tornaria 
propriedade das Nações Indígenas e um regime de cogestão em outras partes dos territórios ancestrais (PAQUET, 2017).

Para Alfred, o contato com o território, em todas as suas formas, torna-se o vetor principal desse retorno a uma visão indígena do mundo. A ligação estreita com o território faz com que a relação com o ambiente e a própria identidade cultural sejam modificadas (PAQUET, 2017). Além disso, considerando o modo como a sociedade majoritária tem se relacionado com a terra e o ecossistema, particularmente sua tendência em reduzir a terra e o mundo natural a um objeto material a ser possuído, comercializado e explorado, Coulthard explica que, mesmo que o valor material da terra seja apreciado pelas sociedades indígenas tradicionais, isso está embutido em uma ordem ética mais ampla.

De acordo com essa ordem ética, a terra é entendida como um complexo "campo de relações" e constitui "uma forma de conhecer, de experimentar e de se relacionar com o mundo e com os outros" (COULTHARD, 2014, p. 61). As pessoas têm obrigações para com a terra, a água, a flora e a fauna da mesma forma que têm com outras pessoas. A ênfase na reconexão com a terra e com o ecossistema tem a ver, para os pensadores do movimento da Resurgence, com a capacidade de manter essas relações visando o futuro e isso é compreendido como um aspecto crucial da coexistência. Nesse tocante, a descolonização nos levaria a ultrapassar os obstáculos que impedem um diálogo para que os acordos políticos futuros busquem soluções mutuamente aceitáveis para estar na terra e aproveitar as variadas oportunidades de vida e de desenvolvimento humano que ela oferece (ELLIOTT, 2018).

Com relação ao mantra que afirma que a "Língua é Poder", Alfred considera a recuperação e valorização das línguas indígenas cruciais para o processo de descolonização. Ele lembra como a violência que foi a perda e o abandono das línguas indígenas em muitas comunidades:

[...] a agressão racista extrema e hostil dos brancos, a degradação social e a assimilação forçada, combinadas à construção de oportunidades econômicas baseadas na fala das línguas europeias, resultou em uma 
decisão compreensível de abandonar as línguas Onkwehonwe e adotar as línguas dos colonizadores. (ALFRED, 2005, p. 247, tradução nossa)

A linguagem é a porta de acesso aos conhecimentos, aos princípios éticos, aos valores e conceitos incorporados em quadros tradicionais. Sendo a língua um repositório de entendimentos, conceitos e padrões de conhecimento particulares que moldam a forma como as pessoas veem o mundo e o reconstroem através das suas interações, Alfred sugere que a recuperação das línguas indígenas deve contribuir para a construção de futuros sociais descolonizados. A recuperação das línguas indígenas é importante não apenas como um modo de resistência, mas também porque ao fazê-lo existe potencial para descobrir "enquadramento(s) alternativo(s) para definir a conduta de uma boa vida e uma noção de justiça entre os povos" (ALFRED 2005 apud ELLIOTT, 2018, p. 15). Sobre a importância da língua, Alfred e Corntassel afirmam:

Não precisamos esperar o colonizador para nos dar dinheiro ou validar a nossa visão de um futuro livre; precisamos apenas começar a usar as nossas línguas indígenas para enquadrar os nossos pensamentos, 0 quadro ético das nossas filosofias, tomar decisões e usar as nossas leis e instituições para nos governarmos a nós mesmos. (ALFRED, 2005, p. 611, tradução nossa)

Recuperar a língua indígena significa recuperar formas de saber fora do quadro mental e ideacional do colonialismo, regenerando-se num universo conceitual formado pelas próprias línguas indígenas. A revitalização das línguas proporcionaria uma revitalização das instituições sócio-políticas indígenas também (PAQUET, 2017).

A alimentação é um outro aspecto crucial no processo de descolonização da forma como pensado pelo movimento Resurgence. O mantra é “Descolonize a sua Dieta" e tem uma relação com a recuperação da autossuficiência não apenas no que diz respeito à capacidade de produzir ou obter sua própria comida, mas também com relação ao vestuário, à habitação e ao acesso a medicamentos. O retorno à uma alimentação tradicional significaria uma diminuição da dependência dos programas sociais do governo e poderia reavivar formas comunitárias de partilha dos produtos da caça, da pesca e da 
colheita. Práticas essas ainda respeitadas em muitas comunidades, como a situação de confinamento por causa da pandemia do Covid-19 pôde comprovar.

Além de reconstruir redes de solidariedade, o retorno à uma alimentação tradicional traria benefícios para a saúde dos indivíduos. Nicolas Paquet lembra que, para as "comunidades do Norte do Canadá, onde o preço dos alimentos é mais caro e somente os alimentos com menor valor nutritivo são acessíveis", uma alimentação mais saudável significaria, sem dúvida, uma melhora na saúde física dos autóctones (2017, p. 50). Nesse aspecto, Alfred não hesita em relacionar a saúde física dos indivíduos com a capacidade das Nações indígenas de recuperarem a sua dignidade. Para Alfred,

A saúde e a cura, verdadeiramente, são alcançadas rejeitando-se o estilo moderno de vida tóxico; a cura física e mental e a reconexão cultural estão ligadas. A saúde física é a manifestação do corpo e da dignidade recuperadas. Quando mentes claras e calmas e corpos fortes estiverem ligados, teremos pessoas inteiras novamente, e trabalhando juntos nos tornaremos Nações fortes e dignas. (ALFRED, 2009a, p. 53, tradução nossa)

O quarto ponto de incidência da Resurgence é a educação. Alfred considera fundamental redirecionar as energias e os recursos para a educação dos jovens indígenas e para o desenvolvimento de uma "intelligentsia indígena". Uma educação enraizada na tradição, deve preparar esses jovens indígenas para proteger e preservar suas Nações e, ao mesmo tempo, criar condições de coexistência harmoniosa com os outros (ALFRED; CORNTASSEL, 2005, p. 177). Ele acredita que escritores, filósofos, professores e artistas indígenas são essenciais para confrontar o Estado em um nível mais profundo (ALFRED; CORNTASSEL, 2005, p. 178).

O quinto mantra trata da reconstituição de relações de tutoria e de ensinoaprendizagem que fomentem um desenvolvimento humano real e significativo e que promovam a solidariedade comunitária. "A mudança acontece em um Guerreiro de cada vez" porque o movimento em direção à descolonização só poderá acontecer a partir de “transformações alcançadas por meio de uma experiência diretamente guiada a grupos 
pequenos e pessoais e com uma orientação de um-a-um para um novo caminho" (ALFRED; CORNTASSEL, 2005, p. 613). O papel dos tutores é crucial para iniciar um processo de regeneração da comunidade que leve os Povos Indígenas para além do desempenho e para o reino de prática quotidiana. Os anciãos e professores terão de se preparar para as responsabilidades renovadas de ajudar outros nas suas reconexões com a terra, com a cultura e com a comunidade (CORNTASSEL, 2012).

O terceiro mantra "A liberdade é o Outro Lado do Medo" trata da necessidade de transcender o controle e o poder das diferentes formas de medo que os poderes coloniais utilizam para dominar e manipular os Povos Indígenas. Para confrontar os medos de frente, uma ação espiritualmente fundamentada se faz necessária (ALFRED; CORNTASSEL, 2005, p. 613).

Esses mantras indicam os caminhos para que as pessoas indígenas possam pôr em prática atitudes ou gestos de Resurgence, à sua maneira, considerando suas necessidades e seu contexto particular. Esses gestos de Resurgence, Alfred lembra, devem acontecer de acordo com o quadro ético que enfatiza a responsabilidade a nível comunitário e o ensino do respeito, da reciprocidade e do não domínio sobre as pessoas, sobre a terra e o meio ambiente (ALFRED, 2005).

\section{Considerações finais}

Superando o campo das críticas para pensar estratégias de ação, Alfred convoca, com sua noção de Resurgence, os Povos Indígenas a se reconectarem com as suas próprias experiências coletivas de vida enquanto Povos Indígenas, pois apenas elas podem produzir os conhecimentos possíveis de serem utilizados para o estabelecimento de estratégias de resistência ao colonialismo. Se o colonialismo é uma "narrativa em que o poder do colonizador é a referência e a suposição fundamental, limitando inerentemente a liberdade indígena e impondo uma visão do mundo que não é senão um resultado ou uma perspectiva desse poder", Alfred argumenta que as ferramentas coloniais - como sua epistemologia, língua e estruturas políticas - não podem ser utilizadas para combater as suas próprias mentiras. O combate ao colonialismo e à 
dominação imposta pelo colonizador devem se fazer por meio da busca incessante pelo conhecimento e, mais importante, pela profunda e verdadeira reconexão com a terra.

Os gestos de Resurgence propostos por Alfred são indícios que mostram os caminhos possíveis para a descolonização. Não se trata de uma "receita" ou "prescrição" a ser seguida. O movimento da Resurgence deve ser concebido como um processo profundamente heterogêneo. Suas manifestações irão inevitavelmente variar de acordo com as especificidades dos contextos locais, das histórias, das culturas, da agência humana e da imaginação. O curso exato do ressurgimento não pode e não deve ser prescrito. "Deve, pelo contrário, ser determinado pela diversidade das comunidades que o perseguem e refletir essa diversidade" (ELLIOTT, 2018, p. 7).

Não se trata tampouco de um apego ao passado ou às tradições. Ao insistir na reconexão com a terra, com a cultura e com a tradição, Taiaiake Alfred não pretende recriar algum tipo de ordem social pré-colonial. Ele propõe o que chama de "tradicionalismo autoconsciente" (self-conscious traditionalism), ou seja,

Uma abordagem que entende a cultura como um processo dinâmico, e o tradicionalismo como uma referência constante entre o que é recordado do passado e o que é demandado a partir das exigências do presente. (ALFRED, 1995, p. 75, tradução nossa)

O "tradicionalismo autoconsciente" é um tradicionalismo que se adequa às exigências de mudança em um ambiente político em transformação, ao mesmo tempo em que recupera vários elementos da cultura em um esforço de afirmação do poder com base nos valores e princípios fundamentais e estáveis dos Mohawk.

O movimento da Resurgence propõe o aproveitamento crítico do "passado com vista a transformar radicalmente as relações de poder colonial que vieram a dominar o nosso presente" (COULTHARD, 2014, p. 157). Não se trata de "ligar as gerações presentes ou futuras a formas essencializadas de organização social e cultural” (ELLIOTT, 2018, p. 7). Trata-se de uma "revitalização seletiva de elementos-chave" de uma cultura já existente, “uma reforma autoconsciente e sincrética que leva à criação de uma identidade e de um 
quadro institucional fortemente enraizado na tradição, mas adaptado à realidade política moderna" (ALFRED, 1995, p. 179). Essa revitalização constitui um primeiro passo rumo à descolonização.

A restauração e revitalização das práticas tradicionais de alimentação, de educação, da língua e a reconexão com o território, nos moldes prensados por Taiaiake Alfred, seriam uma maneira de fortalecer os laços dos povos com suas Nações. Os gestos da Resurgence são práticas de resistência, definem um conjunto de ações feitas por e para os Povos Indígenas sem o envolvimento do Estado ou do grupo majoritário (PAQUET, 2017). A reconexão com o território implica a restauração de uma relação harmoniosa com a terra, o que desafia, enquanto prática de resistência, os modos intensivos de exploração de recursos que são amparados pelos governos e pelas grandes empresas extrativistas. Compreendidos como atos de resistência, os gestos da Resurgence são, assim, estratégias para a descolonização.

Finalmente, o caminho para a descolonização é árduo e cheio de obstáculos, mas necessário diante das ameaças reais que o colonialismo ainda representa. Para Alfred, a única forma para assegurar a sobrevivência dos Povos Indígenas é "recuperar sua força, sua sabedoria e sua solidariedade, honrando e revitalizando os ensinamentos tradicionais" (ALFRED, 1999, p. 11).

\section{Referências}

ALFRED, Taiaiake. Peace, power, righteousness: an indigenous manifesto. Toronto: Oxford University Press. 1999.

ALFRED, Taiaiake. On Canada and its indigenous peoples: Taiaiake Alfred - Mohawk writer and activist speaks about Canada's relationship with indigenous peoples. [Toronto: TVO], 29 Dec. 2003. 1 vídeo (51 min). Disponível em: https://www.tvo.org/video/archive/taiaiakealfred-on-canada-and-its-indigenous-peoples. Acesso em: 20 out. 2020.

ALFRED, Taiaiake. Wasáse: indigenous pathways of action and freedom. North York: University of Toronto Press, 2005. 
ALFRED, Taiaiake. Colonialism and state dependency. Journal of Aboriginal Health, Toronto, p. 42-60, nov. 2009a.

ALFRED, Taiaiake. Restitution is the real pathway to justice for indigenous peoples. In: YOUNGING, Gregory, DEWAR, Jonathan; DEGAGNÉ, Mike (eds.). Response, responsibility, and renewal. Ottawa: Aboriginal Healing Foundation, 2009b. p. 179-187.

ALFRED, Taiaiake. Colonial stains in our existence: imperial arrogances. CANNON, Martin J.; SUNSERI, Lina. Racism, colonialism, and indigeneity in Canada. Toronto: Oxford University Press Canada, 2011. p. 3-10.

ALFRED, Taiaiake. It's all about the land. In: McFARLANE, Peter; SCHABUS, Nicole (eds.). Whose land is it anyway?: a manual for decolonization. Vancouver: Federation of PostSecondary Educators of BC Press, 2017. p. 10-13.

ALFRED, Taiaiake. Don't just resist: return to who you are. The Decolonize Issue: In Depth (online), Bainbridge Island, 9 April 2018. Disponível em:

https://www.yesmagazine.org/issue/decolonize/2018/04/09/dont-just-resist-return-towho-you-are/. Acesso em: 15 nov. 2020.

ALFRED, Taiaiake. 1968-2018 Conference: "From Red Power to Reconciliation". [Burnaby: SFU], 29 nov. 2018. 1 vídeo (47 min). Disponível em: https://www.youtube.com/watch?v=jV_ohK28Pil\&feature=youtu.be. Acesso em: 25 out. 2020.

ALFRED, Taiaiake. It's all about the Land. [Entrevista cedida a] Qwaxw. Radio NuxalK, 21 junho 2020. Disponível em: https://taiaiake.net/. Acesso em: 15 nov. 2020.

ALFRED, Taiaiake; CORNTASSEL, Jeff. Being indigenous: resurgences against contemporary colonialism. Government and Opposition, Edinburgh, v. 4, n. 4, 2005, p. 597-614.

CAL Y MAYOR, Araceli Burguete. Cumbres indígenas en América Latina. [S.I.]: Agencia Internacional Prensa Indígena, 11 abril 2007. Disponível em:

http://www.llacta.org/notic/2007/noto411b.htm\#: :text=Lugares\%20para\%20pensar\%20en \%20la,para\%20refrendar\%20y\%20modificar\%20agendas. Acesso em: 10 nov. de 2020.

CORNTASSEL, Jeff. Re-envisioning resurgence: indigenous pathways to decolonization and sustainable self-determination. Decolonization: Indigeneity, Education \& Society, New Mexico, v. 1, n. 1, 2012, p.86-101.

COULTHARD, Glen. Red skin, white masks: rejecting the colonial politics of recognition. Minneapolis: University of Minnesota Press, 2014. 
ELLIOTT, Michael. Indigenous resurgence: the drive for renewed engagement and reciprocity in the turn away from the state. Canadian Journal of Political Science, Ottawa, n. 51, 2017, p. 1-21.

MCFARLANE, Peter; SCHABUS, Nicole (eds.). Whose land is it anyway?: a manual for decolonization. Vancouver: FPSE, 2017.

PAQUET, Nicolas. Reconnaissance et résurgence: la nécessité d'une approche ascendante dans le contexte colonial Canadien. 89p. 2017. Mémoire (Maîtrise en Philosophie) -

Département de Philosophie, Université du Québec, Montréal, 2017.

Recebido em: 05/12/2020

Aprovado em: 25/02/2021

Universidade do Estado de Santa Catarina - UDESC

Centro de Ciências Humanas e da Educação - FAED

PerCursos

Volume 22 - Número 48 - Ano 2021 revistapercursos@gmail.com 